\title{
Poly(ADP-Ribose) Polymerase Inhibitors (PARPi) for Patients With Advanced Breast Cancer: a Meta- analysis of Randomized Controlled Trials
}

YongCheng Su ( $\sim$ syczb2643937537@163.com )

Xiamen University and Fujian Medical University Affiliated First Hospital https://orcid.org/0000-00016322-7681

\section{XiaoGang Zheng}

Xiamen University and Fujian Medical University Affiliated First Hospital

\section{Research}

Keywords: PARP inhibitors, Advanced Breast Cancer, Randomized Controlled Trials(RCT), Meta-Analysis

Posted Date: July 29th, 2020

DOl: https://doi.org/10.21203/rs.3.rs-48500/v1

License: (c) (1) This work is licensed under a Creative Commons Attribution 4.0 International License.

Read Full License 


\section{Abstract}

BACKGROUND: Poly(ADP-ribose) polymerase (PARP) inhibitors are new class of drugs that are currently being studied in several malignancies. However, datas about the efficacy and safety of the PARP inhibitors are limited. Therefore, we conducted a meta-analysis of randomized controlled trials (RCT) in patients with breast cancer.

METHODS: Pubmed/Medline, Embase, Cochrane Library, and abstracts presented at the annual meeting of the American Society of Clinical Oncology (ASCO) were searched for articles published from 2000 to June 2018.Summary incidences and the RR, HR with 95\% confidence intervals, were calculated by using a random-effects or fixed-effects model.

RESULTS: The summary HR indicated PARPi was not associated with OS $(\mathrm{HR}=0.83,95 \% \mathrm{Cl} 0.66-1.06$, $Z=1.49, P=0.14$ ), while it could significantly improve PFS ande time to deterioration (TTD) of global health status/quality of life(GHS/QoL) as compared with traditional standard therapy, the HR was $0.60(95 \% \mathrm{Cl} 0.50-0.72 ; \mathrm{Z}=5.52, \mathrm{P} \otimes 0.00001)$ and $0.4(95 \% \mathrm{Cl} 0.29-0.54, \mathrm{z}=5.80, \mathrm{p}=0.000)$,respectively. The RR of grade 3 or more anemia ,fatigue and headache was $3.02\left(95 \% \mathrm{Cl}, 0.69-13.17 ; p=0.14, I^{2}=90 \%\right), 0.77$ $\left(95 \% \mathrm{Cl}, 0.34-1.73 ; \mathrm{p}=0.52, \mathrm{I}^{2}=7 \%\right)$ and $1.13\left(95 \% \mathrm{Cl}, 0.30-4.18 ; \mathrm{p}=0.86, \mathrm{I}^{2}=0 \%\right)$, respectively.

CONCLUSION: The findings of this meta-analysis showed that PARPi has no significant effect on OS, while it could significantly improve in PFS and TTD of GHS/QoL for patients with advanced or metastatic breast cancer.Furthermore,our findings also demonstrated that the PARPi treatment is connected with an increased risk of grade 3 or more anemia adverse events.

\section{Introduction}

Breast tumor is the most popular female malignancy, with an estimated 1 million new cases diagnosed in 2012 (a quarter of all cancers[1].In 2016, there were approximately 246660 women diagnosed with breast tumor within America. Recent decades have shown significant progress with the therapy of breast tumor. Human epidermal growth factor receptor type 2 (HER2)-targeted therapies and Endocrine treatment have received a substantial improvement in overall survival(OS) in patients with HER2-positive and hormone receptor(HR) positive breast tumor[1]. Despite extensive research, triple-negative (estrogen receptor (ER),progesterone receptor (PR) negative,and HER2-negative) breast cancers (TNBC), still lack specific methods for therapy[3].At present, the mainstay of treatment for triple-negative breast cancer and BRCA associated triple-negative is still chemotherapy.

Poly (adenosine diphosphate-ribose) polymerase (PARP) is a novel therapeutic target in cancer,which can bind to DNA breaks and attract DNA repair proteins to the site of damage to facilitates DNA repair[4].Poly (adenosine diphosphate-ribose) polymerase (PARP) is a novel therapeutic target in cancer,which can bind to DNA breaks and attract DNA repair proteins to the site of damage to facilitates DNA repair[5].Those people whose breast cancer susceptibility genes (BRCA1 and BRCA2) mutations, have a high risk of developing breast tumor[6]. 
PARP inhibitors have played a crucial role in the repair of DNA single-strand breaks by the base excision repair (BER) pathway[7]. PARP inhibitors are oral small-molecule inhibitors of PARP enzymes 1,2 , and 3,which can improve the clinical activity of DNA-damaging Chemotherapy by blocking DNA damage repair[8]. PARP inhibition could cause "synthetic lethality" in BRCA mutant tumor cells,which leads to profound cytotoxicity to tumor cells while sparing healthy cells[4, 9].Because only the tumors in BRCA $1 / 2$ mutated patients are defective in homologous recombination,therapy with PARP inhibitors appears to be highly tumour-specific[4].

Olaparib is a newfangled of PARP inhibitor which can induce synthetic lethality in homozygous BRCAdeficient cells[10].Olaparib was permitted to treat advanced ovarian cancer patients with malignant germline BRCA-mutated, who have been treated with three or more prior lines of chemotherapy[11].Furthermore the SOLO1 trial showed that BRCA1/2 mutation and newly diagnosed advanced ovarian cancer patients who have accepted platinum-based chemotherapy, the use of maintenance therapy with olaparib would provide a substantial benefit concerning progression free survival(PFS)[12].The SOL01 trial, which approved olaparib as maintenance therapy of ovarian cancer patients who were sensitive to platinum therapy.

The OlympiAD trial demonstrated that compared to standard therapy,olaparib provided a remarkable benefit among patients with a germline BRCA mutation and HER2-negative metastatic breast tumor[13].OlympiAD trial that gave the approval of olaparib by the FDA for the therapy of patients with BRCA-mutated HER2-negative metastatic breast tumor patients[14].

Talazoparib, is another oral inhibitor of PRAP.The phase III trial EMBRACA showed that compared to standard chemotherapy, single-agent talazoparib provided a significant benefit concerning PFS among patients with germline BRCA1/2 mutation advanced breast cancer.Talazoparib was recently approved as the therapy of people with malignant or suspected malignant germline BRCA-mutated, HER2-negative, locally advanced or metastatic breast cancer by FDA and the European Medicines Agency $(E M A)[15,16]$.

As a new drug, it is vital to understand its adverse effects profile better to optimize its use. However, data about the efficacy and safety of the PARPi are limited. Few studies have investigated the PARPi in any systematic way. Therefore, the purpose of this meta-analysis is to review recent research to evaluate the efficacy and safety of PARP inhibitors.

\section{Materials And Methods}

\subsection{Data source}

A literature search was independently performed by two investigators using electronic databases including Pubmed/Medline,

Embase and Cochrane Library, using the following search keywords: "Olaparib" or "PARPi" or "Talazoparib" and“Randomized” and "Advanced Breast Cancer" restricted to randomized controlled trials 
(RCT) published in English. We also searched abstracts and virtual meeting presentations from the American Society of Clinical Oncology (http://www.asco.org/ASCO) conferences held between January 2000 and September 2019. What's more, we searched the clinical trial registration website (http://www.ClinicalTrials.gov) to obtain information on prospective registration trials. When more than one publication was identified from the same clinical trial, we used the most recent or complete report of that trial. When data could not be determined, we would contact the authors.

\subsection{Selection criteria}

Studies should meet the following criteria of eligibility: 1) articles published in English language, 2) prospective phase II or III randomized controlled trials (RCT) design in advanced breast cancer patients; 3) participants assigned to treatment with PARPi or control (placebo, chemotherapy or other therapies)and,4)studies with available safety data reporting adverse events.

\subsection{Data extraction and quality assessment}

Two experienced investigators independently performed data extraction[17]. Different variables from each eligible study were extracted: first author's name, publication year, trial phase, number of enrolled patients, dosing schedules used in PARPi and control arms, CTCAE (Common Terminology Criteria for Adverse Events) version, median progression-free survival, median overall survival,number of patients for analysis and number of the selected adverse events. We assessed the methodological quality of the included trials using the Cochrane Collaboration tool[18]. Studies were graded as having a "low risk", "high risk",or "unclear risk" of bias across the seven specified do-mains. We also used the seven-point Jadad ranking system that included randomization, double-blinding, and withdrawals, a practice in agreement with other meta-analyses done in this context[19].

\subsection{Statistical analysis}

In this meta-analysis, the software Stata 15.0 and review manager 5.3 as used to pool the results of eligible studies. The H.R. with it,s $95 \% \mathrm{Cl}$ was used to evaluate the influence strength of the PARPi on the prognosis of advanced breast cancer patients for each study. Q statistics and $\mathrm{I}^{2}$ statistics evaluated the

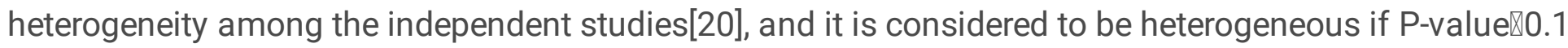
or $1^{2} \llbracket 50 \%$. The fixed-effects model would be adopted if there was no heterogeneity among studies; otherwise, we would use the random-effects model[21]. Publication bias was evaluated through funnel plots and quantified by the Begg [22]and Egger tests. A symmetrical plot and P-value of Egger,s test ( $\mathbb{Z}$ 0.05) suggested that there was no publication bias in all studies[23].

\section{Results}

\subsection{Search results}


The search strategy yielded a total of 130 publications. Fig. 1 provides an overview of the literature search and study selection. After removal of duplicates, 82 studies remained for the screening of titles and abstracts. Of these, 31 potentially relevant publications were selected for full-text reading. After the full-text screening, 3 RCTs reported in 8 publications were included in the systematic review[24-31], and all of them provided sufficient data for quantitative synthesis of the overall survival of advanced breast cancer patients by meta-analysis.

\subsection{Study quality}

All included trials were randomized, with 1 phase 2 trials[30]®2 phase 3 trials[24, 29] were published in full manuscript, and one trial was presented at the ASCO meeting[32]. Using the Cochrane Collaboration tool for risk of bias classification, we found the quality of the included studies to be generally good and fair(fig. 2). Trials were also ranked for the Jadad score, with all trials categorized as being of good quality (achieving a score of 4 or more)[19]. All three trials reported adverse events according to the National Cancer Institute's CTCAE version 3 or 4 criteria.

\subsection{Patients}

The baseline characteristics of the enrolled studies are presented in table 1. A total of 926 patients were available for the meta-analysis (PARPi: 587; controls/placebo: 339)with median age ranging from 44 to 50 years. The most commonly mutated gene was BRCA1, in 757 of patients, followed by BRCA2 in 329 . All three included studies reported safety data on adverse events and were included in the analysis. In one trial, randomization was between chemotherapy/control and PARPi olaparib[33]. Another study, PARPi Talazoparib, was compared to Standard-Therapy for advanced breast cancer[24].Since there are few randomized controlled trials related to PARPi monotherapy for advanced breast cancer, to improve the reliability of our conclusion,we added another trial that PARPi Veliparib was combined with Carboplatin/Paclitaxel[30]. All of the three included studies provided OS and PFS data of patients with breast cancer. (table1).

\subsection{Data synthesis}

The primary endpoint of OS in patients with advanced breast cancer was evaluated in 926 patients. No significant heterogeneity was found (chi-squared $=0.54, \mathrm{df}=2, \mathrm{P}=0.76, \mathrm{I}^{2}=0 \%$ ), and fixed effects model was utilized to calculate the pooled $\mathrm{HR}$ and $95 \% \mathrm{Cl}$. The combined results indicated that PARPi was associated with lower mortality (HR $0.83,95 \% \mathrm{Cl} 0.66-1.06, \mathrm{Z}=1.49, \mathrm{P}=0.14$ deficient quality of evidence). Patients with advanced breast cancer who received PARPi had $17 \%$ lower mortality than those who received other Standard-Therapy during the study period, but this difference was not statistically significant (fig 3.)

The primary endpoint of progression-free survival in patients with advanced breast cancer was evaluated in 926 patients. No significant heterogeneity was found (chi-squared $=2.55, \mathrm{df}=2, \mathrm{P}=0.28, \mathrm{I}^{2}=22 \%$ ), so we used fixed-effects model to calculate the pooled $\mathrm{HR}$ and $95 \% \mathrm{Cl}$.The pooled results demonstrated that 


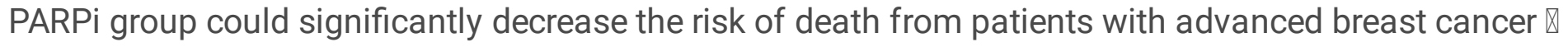
compared with the control group, which was only $60 \%$ of the control group(HR $0.60,95 \% \mathrm{Cl} 0.50$ to 0.72 ; $Z=5.52, P \otimes 0.00001)$ and the results were statistically significant. (fig4.)

Two studies assessed the time to deterioration (TTD) of global health status/quality of life(GHS/QoL),the HR for TTD was 0.4 (95\% Cl 0.29-0.54,Supplementary Fig.1). No significant heterogeneity was found( $P=$ $0.671, I^{2}=0 \%$, the pooled HR suggested that PARPi treatment can lead to a statistically significant delay in TTD in patients with advanced breast cancer .

\subsection{Sensitivity Analysis}

The root of heterogeneity was assessed by sensitivity analysis, and there was not apparent heterogeneity was detected as described above. Besides, the pooled HR was not affected by any individual study, as shown in sensitivity analyses, which demonstrated that the results of our meta-analysis were robust and stable(fig.5.)

\subsection{Publication bias}

No evidence of publication bias was detected for OS or PFS of PARPi group by either the Begg's or the Egger's test (for PFS of PARPi group Begg's $P=0.296$ and Egger's $P=0.116$; for OS of PARPi group Begg's $P=1.000$ and Egger's $P=0.653)[22,23]$.

\subsection{Incidence and relative risk of adverse events}

Using a random-effects model, the summary incidence of all-grade and grade 3 or more adverse events in PARPi-treated patients was $98 \%$ (heterogeneity: $I^{2}=0 \%, p=0.43$ ) and $47 \%$ (heterogeneity: $I^{2}=98 \%, p<$ 0.00001 ), while in non-PARPi patients was $97 \%$ (heterogeneity: $I^{2}=0, p=0.66$ ) and $53 \%$ (heterogeneity: $I^{2}=$ $100 \%, \mathrm{p}<0.00001)$. The relative-risk (RR) of all-grade and grade 3 or more adverse events compared to non-PARPi was $1.02(95 \% \mathrm{Cl}, 0.99-1.04 ; \mathrm{p}=0.16)$ and $0.90(95 \% \mathrm{Cl}, 0.78-1.03 ; \mathrm{p}=0.13)$ ) while this difference was not statistically significant .(Fig. 7)

We were also using a random-effects model to calculate the summary incidence of all-grade and grade 3 or more anemiafatigue and headache events in PARPi-treated patients. the RRs of all-grade anemia , fatigue and headache events were $1.68\left(95 \% \mathrm{Cl}, 0.93-3.03 ; p=0.08 \mathrm{Zl}^{2}=89 \%\right), 1.05(95 \% \mathrm{Cl}, 0.83-1.34 ; \mathrm{p}=$ $\left.0.67 \mathrm{Xl} \mathrm{I}^{2}=50 \%\right)$ and $1.29\left(95 \% \mathrm{Cl}, 1.01-1.65 ; \mathrm{p}=0.04 \otimes \mathrm{I}^{2}=0 \%\right)$ (Fig. 9). There were significant heterogeneity in anemia $\left(P=0.0001,1^{2}=89 \%\right)$ and fatigue $\left(P=0.13,1^{2}=50 \%\right)$, when evaluating only trials that PARPi was given as monotherapy, the RR of all-grade anemia or fatigue events were $2.09(95 \% \mathrm{Cl}, 1.10-3.97 ; p=0.02 \rrbracket$ $\left.\mathrm{I}^{2}=82 \%\right)$ and $1.19\left(95 \% \mathrm{Cl}, 0.97-1.45 ; \mathrm{p}=0.10 \otimes \mathrm{l}^{2}=0 \%\right)(\mathrm{Fig} .8)$.

The RRs of grade 3 or more anemia , fatigue and headache events were $3.02(95 \% \mathrm{Cl}, 0.69-13.17 ; \mathrm{p}=$ $\left.0.14, I^{2}=90 \%\right), 0.77\left(95 \% \mathrm{Cl}, 0.34-1.73 ; \mathrm{p}=0.52, \mathrm{I}^{2}=7 \%\right)$ and $1.13(95 \% \mathrm{Cl}, 0.30-$ $\left.4.18 ; p=0.86, I^{2}=0 \%\right)$,respectively.Significant heterogeneity in anemia was found, when excluded the trial 
that PARPi was in combination with chemotherapy, the RR of grade 3 or more anemia was $5.88(95 \% \mathrm{Cl}$,

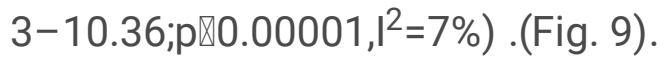

As a consequence,PARPi treatment was associated with a significant increase in the incidence and risk of any-grade anemia $\left.\triangle \mathrm{RR}=2.0995 \% \mathrm{Cl}, 1.10-3.97 ; \mathrm{p}=0.02 \mathrm{Vl}^{2}=82 \%\right)$ and headache $(\mathrm{RR}=1.29,95 \% \mathrm{Cl} 1.01$ $1.65 ; p=0.04,1^{2}=0 \%$ ), the RR of PARPi associated all-grade anemia has significant heterogeneity(Fig.9).Moreover,PARPi treatment was associated with a significant increase in the incidence and risk of grade 3 or more anemia events (RR=5.88 95\% Cl, 3-10.36; $\mathbb{p} \otimes .00001, \mathrm{I}^{2}=7 \%$ ), and this difference was statistically significant.

\section{Discussion}

The meta-analysis identified 3 RCTs involved 926 advanced or metastatic breast cancer patients. The summary HRs indicated PARP inhibitors were not associated with OS (HR= 0.83,95\% Cl 0.66-1.06, Z=1.49, $\mathrm{P}=0.14$ shallow quality of evidence), while it could significantly improve PFS compared to patients treated with traditional standard therapy $(\mathrm{HR}=0.60,95 \% \mathrm{Cl} 0.50-0.72 ; \mathrm{Z}=5.52, \mathrm{P} \otimes 0.00001)$. Moreover, according to results of global health status/quality of life(GHS/QoL),we also observed a significant delay in time to deterioration (TTD) compared to patients who were treated with traditional standard chemotherapy.

Concerning all-grade and grade 3 or more adverse events,there are not statistically remarkable differences between PARP inhibitors and control group. The relative risk (RR) of all-grade and grade 3 or more adverse events compared to control group was $1.02(95 \% \mathrm{Cl}, 0.99-1.04 ; \mathrm{p}=0.16)$ and $0.90(95 \% \mathrm{Cl}, 0.78-1.03 ; \mathrm{p}=$ 0.13)(Fig. 8). significantly increased risk of all-grade and grade 3 or more anemia events associated with PARPi treatment in advanced or metastatic breast cancer patients. The RR of all-grade and grade 3 or more anemia was $\left.\triangle \mathrm{RR}=2.0995 \% \mathrm{Cl}, 1.10-3.97 ; \mathrm{p}=0.02, \mathrm{I}^{2}=82 \%\right)$ and $5.88(95 \% \mathrm{Cl}, 3-10.36 ; \mathrm{p} \rrbracket$ $0.00001, I^{2}=7 \%$,respectively. Whereas there was significant heterogeneity in all-grade anemia.

Our findings also suggest that the PARP inhibitors treatment are connected with a growing risk of allgrade headache ,the pooled RR was $1.29\left(95 \% \mathrm{Cl}, 1.01-1.65 ; \mathrm{p}=0.04, \mathrm{I}^{2}=0 \%\right)$, the results were statistically significant.

MEDIOLA Trial ,a Phase II study of olaparib and durvalumab in patients with germline BRCA-mutated metastatic breast tumor.The updated results of MEDIOLA Trial showed that the most common grade 3 or more adverse events were anemia ,neutropenia and pancreatitis.And the data also suggest that patients with two prior lines of chemotherapy had shorter median PFS ,median duration of response (mDoR), and median OS ,lower objective response rate (ORR) than those with fewer prior lines of chemotherapy[34].Furthermore,the updated results in the phase 3 EMBRACA and phase 2 ABRAZO trial showed that a higher TALA exposure was related to a higher risk of anemia and thrombocytopenia[35].All these findings support the conclusion of this meta-analysis. 
About EORTC QLQ-C30 symptoms and functioning subscales,the EMBRACA phase III trial showed that compared to the PCT arm,patients who treated with TALA significantly delayed TTD in all symptoms[25].Meanwhile,there is similar result in the OlympiAD trial,except vomiting/nausea symptom score compared with TPC arm[36].

Our work has some limitations. First, there is significant heterogeneity between PARPi and all-grade fatigue,we failed to find the source of heterogeneity.Several reasons may account for the heterogeneity;1) Differences in PARP inhibitors type and the dose may lead to heterogeneity; 2)fatigue is very subjective[37],the evaluated patient-reported outcomes in this regard seem to be better. Furthermore, we used adverse events data reported according to the NCI CTCAE grading system that also includes the subjectivity of the investigators when grading the event. All of these may partly explain the significant heterogeneity between studies. Second, randomized controlled trials about PARP inhibitors for patients with advanced breast cancer are too limited to perform a subgroup analysis study.

In conclusion,the findings of this meta-analysis showed that PARP inhibitors have no significant effect on OS, while it could significantly improve in PFS and TTD of GHS/QoL for patients with advanced or metastatic breast cancer. Furthermore, this meta-analysis also suggested that PARP inhibitors are associated with a significant increase in the risk of all-grade headache and anemia adverse events .Our findings demonstrated that the PARP inhibitors treatment is connected with an increased risk of grade 3 or more anemia adverse events.

\section{Declarations}

\section{Funding}

This research did not receive any specific grant from funding agencies in the public, commercial, or notfor-profit sectors.

\section{Disclosure}

The authors declared no conflicts of interest.

\section{References}

1. Liang H, Tan AR. PARP inhibitors. Current Breast Cancer Reports 2011;3: 44-54.

2. Siegel RL, Miller KD, Jemal A. Cancer statistics, 2016. CA Cancer J Clin 2016;66: 7-30.

3. Metzger-Filho O, Tutt A, de Azambuja E, Saini KS, Viale G, Loi S, et al. Dissecting the heterogeneity of triple-negative breast cancer. J Clin Oncol 2012;30: 1879-87.

4. Bryant HE, Schultz N, Thomas HD, Parker KM, Flower D, Lopez E, et al. Specific killing of BRCA2deficient tumours with inhibitors of poly(ADP-ribose) polymerase. Nature 2005;434: 913-7. 
5. Jones P, Wilcoxen K, Rowley M, Toniatti C. Niraparib: A Poly(ADP-ribose) Polymerase (PARP) Inhibitor for the Treatment of Tumors with Defective Homologous Recombination. J Med Chem 2015;58: 3302-14.

6. Tutt A, Bertwistle D, Valentine J, Gabriel A, Swift S, Ross G, et al. Mutation in Brca2 stimulates errorprone homology-directed repair of DNA double-strand breaks occurring between repeated sequences. Embo J 2001;20: 4704-16.

7. Jiang X, Li X, Li W, Bai H, Zhang Z. PARP inhibitors in ovarian cancer: Sensitivity prediction and resistance mechanisms. J Cell Mol Med 2019;23: 2303-13.

8. Isakoff SJ, Puhalla S, Domchek SM, Friedlander M, Kaufman B, Robson M, et al. A randomized Phase II study of veliparib with temozolomide or carboplatin/paclitaxel versus placebo with carboplatin/paclitaxel in BRCA1/2 metastatic breast cancer: design and rationale. Future Oncol 2017;13: 307-20.

9. Farmer H, McCabe N, Lord CJ, Tutt AN, Johnson DA, Richardson TB, et al. Targeting the DNA repair defect in BRCA mutant cells as a therapeutic strategy. Nature 2005;434: 917-21.

10. Audeh MW, Carmichael J, Penson RT, Friedlander M, Powell B, Bell-McGuinn KM, et al. Oral poly(ADPribose) polymerase inhibitor olaparib in patients with BRCA1 or BRCA2 mutations and recurrent ovarian cancer: a proof-of-concept trial. Lancet 2010;376: 245-51.

11. Kim G, Ison G, McKee AE, Zhang H, Tang S, Gwise T, et al. FDA Approval Summary: Olaparib Monotherapy in Patients with Deleterious Germline \&lt;em\&gt;BRCA\&lt;/em\&gt;-Mutated Advanced Ovarian Cancer Treated with Three or More Lines of Chemotherapy. Clin Cancer Res 2015;21: 4257.

12. Moore K, Colombo N, Scambia G, Kim BG, Oaknin A, Friedlander M, et al. Maintenance Olaparib in Patients with Newly Diagnosed Advanced Ovarian Cancer. N Engl J Med 2018;379: 2495-505.

13. Robson M, Im SA, Senkus E, Xu B, Domchek SM, Masuda N, et al. Olaparib for Metastatic Breast Cancer in Patients with a Germline BRCA Mutation. N Engl J Med 2017;377: 523-33.

14. Astra-Zeneca LYNPARZA Prescribing Information (accessed Nov. 5th, 2018). https://www.accessdata.fda.gov/drugsatfda_docs/label/2017/208558s000lbl.pdf..

15. Hoy SM. Talazoparib: First Global Approval. Drugs 2018;78: 1939-46.

16. Guney EG. Talazoparib to treat BRCA-positive breast cancer. Drugs Today (Barc) 2019;55: 459-67.

17. Moher D, Liberati A, Tetzlaff J, Altman DG. Preferred Reporting Items for Systematic Reviews and Meta-Analyses: The PRISMA Statement. J Clin Epidemiol 2009;62: 1006-12.

18. Higgins JPT, Altman DG, Gøtzsche PC, Jüni P, Moher D, Oxman AD, et al. The Cochrane Collaboration's tool for assessing risk of bias in randomised trials. BMJ 2011;343: d5928.

19. Jadad AR, Moore RA, Carroll D, Jenkinson C, Reynolds DJM, Gavaghan DJ, et al. Assessing the quality of reports of randomized clinical trials: Is blinding necessary? Controlled Clinical Trials 1996;17: 1-12.

20. Higgins JPT, Thompson SG, Deeks JJ, Altman DG. Measuring inconsistency in meta-analyses. BMJ 2003;327: 557. 
21. DerSimonian R, Laird N. Meta-analysis in clinical trials. Controlled Clinical Trials 1986;7: 177-88.

22. Begg CB, Mazumdar M. Operating Characteristics of a Rank Correlation Test for Publication Bias. Biometrics 1994;50: 1088-101.

23. Egger M, Smith GD, Schneider M, Minder C. Bias in meta-analysis detected by a simple, graphical test. BMJ 1997;315: 629.

24. Litton JK, Rugo HS, Ettl J, Hurvitz SA, Gonçalves A, Lee KH, et al. Talazoparib in Patients with Advanced Breast Cancer and a Germline BRCA Mutation. 2018;379: 753-63.

25. Ettl J, Quek R, Lee KH, Rugo HS, Hurvitz S, Goncalves A, et al. Quality of life with talazoparib versus physician's choice of chemotherapy in patients with advanced breast cancer and germline BRCA1/2 mutation: patient-reported outcomes from the EMBRACA phase III trial. Ann Oncol 2018;29: 1939-47.

26. Ettl J, Hurvitz SA, Rugo HS, Lee KH, Mina LA, Woodward NE, et al. Outcomes of talazoparib (TALA) versus physician's choice of chemotherapy (PCT) in patients (pts) with advanced breast cancer $(A B C)$ and a germline BRCA (gBRCA) mutation by line of chemotherapy (CT) in the EMBRACA trial. $J$ Clin Oncol 2019;37.

27. Robson M, Tutt A, Balmana J, Kaufman B, Garber J, Geyer C, et al. OlympiA, Neo-Olympia and OlympiAD: randomized phase III trials of olaparib in patients (pts) with breast cancer (BC) and a germline BRCA1/2 mutation (gBRCAm). 2015;75.

28. Ettl J, Quek RGW, Hurvitz SA, Goncalves A, Tudor IC, Rugo HS. Hospitalization and supportive care medication (SCM) utilisation in patients (pts) with advanced breast cancer (ABC) and a germline BRCA1/2 mutation (gBRCAm) in EMBRACA. Ann Oncol 2019;30: i52.

29. Robson M, Hettle R, Degboe A, Saunders O, Cain T, Kilvert H, et al. Estimating the health state utility of patients with HER2-gBRCA + metastatic breast cancer treated with olaparib or chemotherapy via a mapping analysis of EORTC QLQ-C30 data collected in the olympiad clinical trial. 2018;21: S12.

30. Han HS, Dieras V, Robson ME, Palacova M, Marcom PK, Jager A, et al. Efficacy and tolerability of veliparib $(V ; A B T-888)$ in combination with carboplatin $(C)$ and paclitaxel $(P)$ vs placebo $(P l c)+C / P$ in patients (pts) with BRCA1 orBRCA2 mutations and metastatic breast cancer: a randomized, phase 2 study. 2017;77.

31. Litton J, Ettl J, Hurvitz SA, Mina LA, Rugo HS, Lee K, et al. A phase 3, open-label, randomized, 2-arm international study of the oral dual PARP inhibitor talazoparib in germline BRCA mutation subjects with locally advanced and/or metastatic breast cancer (EMBRACA). 2017;77.

32. OlympiAD final overall survival and tolerability results: Olaparib versus chemotherapy treatment of physician ' $s$ choice in patients with a germline BRCA mutation and HER2-negative metastatic breast cancer.

33. Tutt A, Kaufman B, Garber J, Gelber R, McFadden E, Goessl C, et al. OlympiA: a randomized phase III trial of olaparib as adjuvant therapy in patients with high-risk HER2-negative breast cancer (BC) and a germline BRCA1/2 mutation (gBRCAm). 2017;28: v67.

34. Domchek S, Postel-Vinay S, Im S, Park YH, Delord J, Italiano A, et al. 11910Phase II study of olaparib (O) and durvalumab (D) (MEDIOLA): Updated results in patients (pts) with germline BRCA-mutated 
(gBRCAm) metastatic breast cancer (MBC). Ann Oncol 2019;30.

35. Elmeliegy M, Yu Y, Litton JK, Turner NC, Czibere A, Wilson GG, et al. 306PExposure-safety analyses in breast cancer patients with germline BRCA1/2 mutations receiving talazoparib (TALA) in EMBRACA and ABRAZO trials. Ann Oncol 2018;29.

36. Robson M, Ruddy KJ, IM S, Senkus E, Xu B, Domchek SM, et al. Patient-reported outcomes in patients with a germline BRCA mutation and HER2-negative metastatic breast cancer receiving olaparib versus chemotherapy in the OlympiAD trial. Eur J Cancer 2019;120: 20-30.

37. Mock V, Atkinson A, Barsevick A, Cella D, Cimprich B, Cleeland C, et al. NCCN Practice Guidelines for Cancer-Related Fatigue. Oncology (Williston Park) 2000;14: 151-61.

\section{Tables}

Table1. Baseline characteristics of the included trials in final analysis

\begin{tabular}{|c|c|c|c|c|c|c|c|c|c|c|}
\hline \multirow[t]{2}{*}{$\begin{array}{l}\text { Author } \\
\text {, year }\end{array}$} & \multirow[t]{2}{*}{$\begin{array}{c}\text { Patients } \\
\text { Enrolle } \\
\text { d }\end{array}$} & \multirow[t]{2}{*}{$\begin{array}{l}\text { Treatment } \\
\text { arms }\end{array}$} & \multirow[t]{2}{*}{$\begin{array}{c}\text { Median } \\
\text { age,(rang } \\
\text { e) }\end{array}$} & \multicolumn{2}{|c|}{$\begin{array}{l}\text { BRCA- } \\
\text { status }\end{array}$} & \multicolumn{2}{|c|}{$\begin{array}{c}\text { Hormone-receptor } \\
\text { status }\end{array}$} & \multirow[t]{2}{*}{$\begin{array}{c}\text { Median } \\
\text { OS, } \\
\text { months } \\
(95 \% \mathrm{CI})\end{array}$} & \multirow[t]{2}{*}{$\begin{array}{c}\text { Median PFS, } \\
\text { months } \\
(95 \% \mathrm{CI})\end{array}$} & \multirow[t]{2}{*}{$\begin{array}{r}\text { Jadad } \\
\text { score }\end{array}$} \\
\hline & & & & $\begin{array}{c}\text { Brca- } \\
1, \mathrm{n}\end{array}$ & $\begin{array}{l}\text { Brca } \\
-2, n\end{array}$ & $\begin{array}{c}\text { Hormon } \\
\text { e-recept } \\
\text { or } \\
\text { positive }\end{array}$ & $\begin{array}{c}\text { Triple } \\
\text { negative }\end{array}$ & & & \\
\hline \multirow[t]{2}{*}{$\begin{array}{l}\text { Robso } \\
\text { n } 2019\end{array}$} & 205 & Olaparib & $44(22-76)$ & 114 & 50 & 103 & 102 & 19.3(nr) & $7(5.7-8.3)$ & 5 \\
\hline & 97 & $\begin{array}{l}\text { Standard } \\
\text {-chemotherapy }\end{array}$ & $45(24-68)$ & 84 & 45 & 49 & 48 & 17.1(nr) & $4.2(2.8-4.3)$ & \\
\hline \multirow[t]{2}{*}{$\begin{array}{l}\text { litton } \\
2017\end{array}$} & 287 & Talazoparib & $45(27-84)$ & 133 & 63 & 157 & 130 & $\begin{array}{l}22.3(18.1 \\
-26.2)\end{array}$ & $8.6(7.2-9.3)$ & 4 \\
\hline & 144 & $\begin{array}{l}\text { Standard- } \\
\text { Therapy }\end{array}$ & $50(24-88)$ & 154 & 81 & 60 & 84 & $\begin{array}{l}19.5(16.3 \\
-22.4)\end{array}$ & $5.6(4.2-6.7)$ & \\
\hline \multirow[t]{2}{*}{$\begin{array}{l}\text { Han } \\
2017\end{array}$} & & $\begin{array}{l}\text { Veliparib+Car } \\
\text { boplatin/Paclit } \\
\text { axe }\end{array}$ & $44(25-65)$ & 51 & 44 & 57 & 40 & $\begin{array}{l}28.3(22.4 \\
-n r)\end{array}$ & $\begin{array}{l}14.1(11.5-16 . \\
2)\end{array}$ & 5 \\
\hline & & $\begin{array}{l}\text { Placebo+Carb } \\
\text { oplatin/Paclita } \\
\text { xe }\end{array}$ & $46(24-66)$ & 53 & 46 & 56 & 42 & $\begin{array}{l}25.9(18.1 \\
-34.8)\end{array}$ & $\begin{array}{l}12.3(9.3-14.5 \\
)\end{array}$ & \\
\hline
\end{tabular}

\section{Figures}




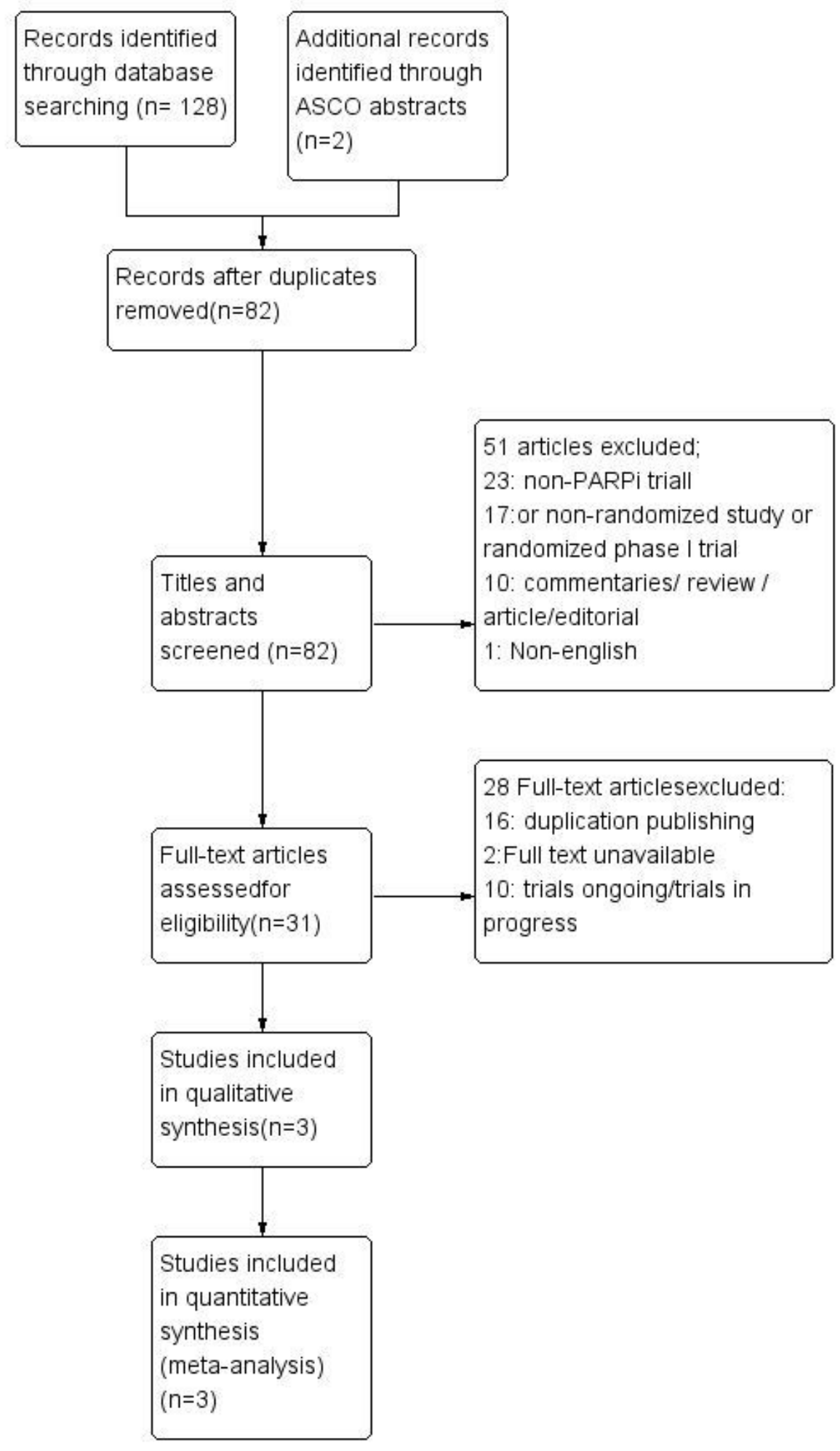

\section{Figure 1}

Study selection. PRISMA flow chart summarizing the process of selection of eligible studies. 
a

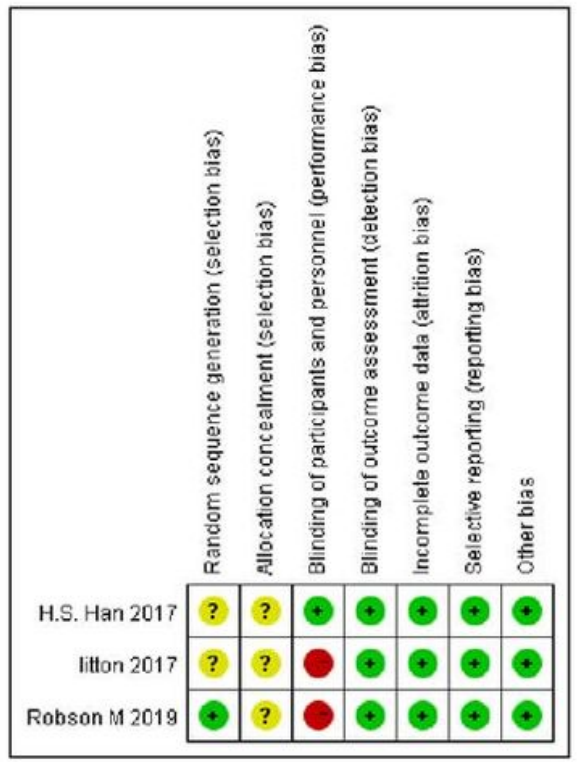

b

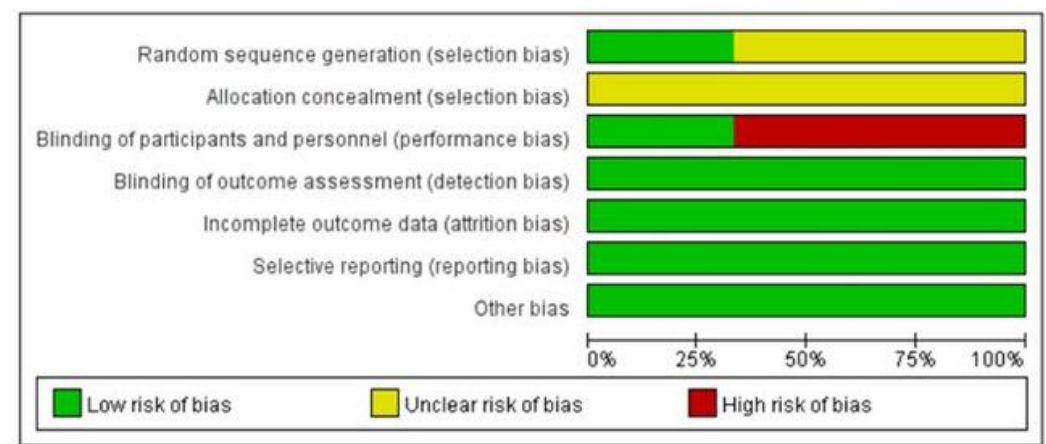

Fig.2 a. Methodological Quality of Included Studies b. Bias risk in the included randomized controlled trials

\section{Figure 2}

A: Methodological Quality of Included Studies. B : Bias risk in the included randomized controlled trials.

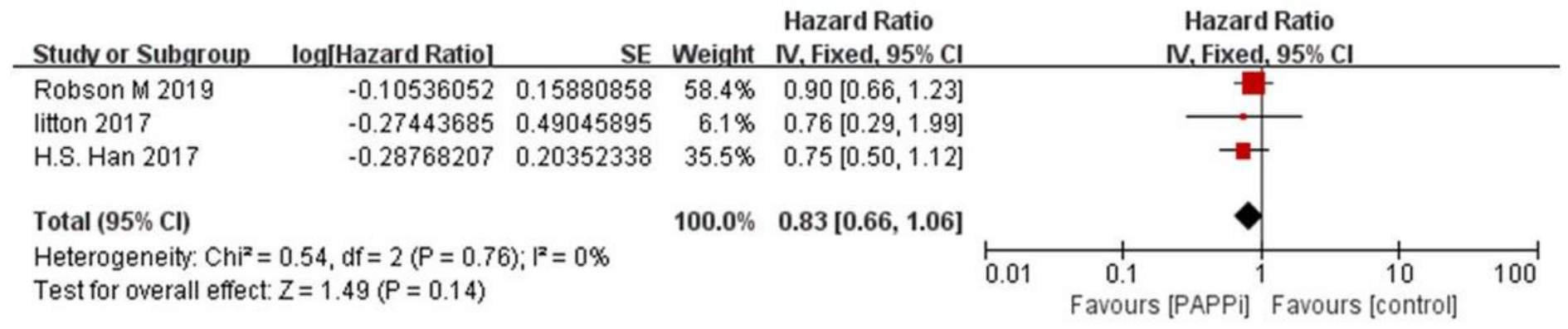

\section{Figure 3}

Hazard Ratio for overall survival with Poly(ADP-Ribose) Polymerase Inhibitors (PARPi) vs. control.

\begin{tabular}{lrrrrrr} 
Study or Subgroup & log[Hazard Ratio] & SE & Weight & $\begin{array}{c}\text { Hazard Ratio } \\
\text { N. Fixed, 95\% Cl }\end{array}$ & \multicolumn{2}{c}{$\begin{array}{c}\text { Hazard Ratio } \\
\text { IV. Fixed, 95\% } \mathrm{Cl}\end{array}$} \\
\hline Robson M 2019 & -0.54472718 & 0.15837411 & $33.9 \%$ & $0.58[0.43,0.79]$ &
\end{tabular}

\section{Figure 4}

Hazard Ratio for progression-free survival with Poly(ADP-Ribose) Polymerase Inhibitors (PARPi) vs. nonPARPi 

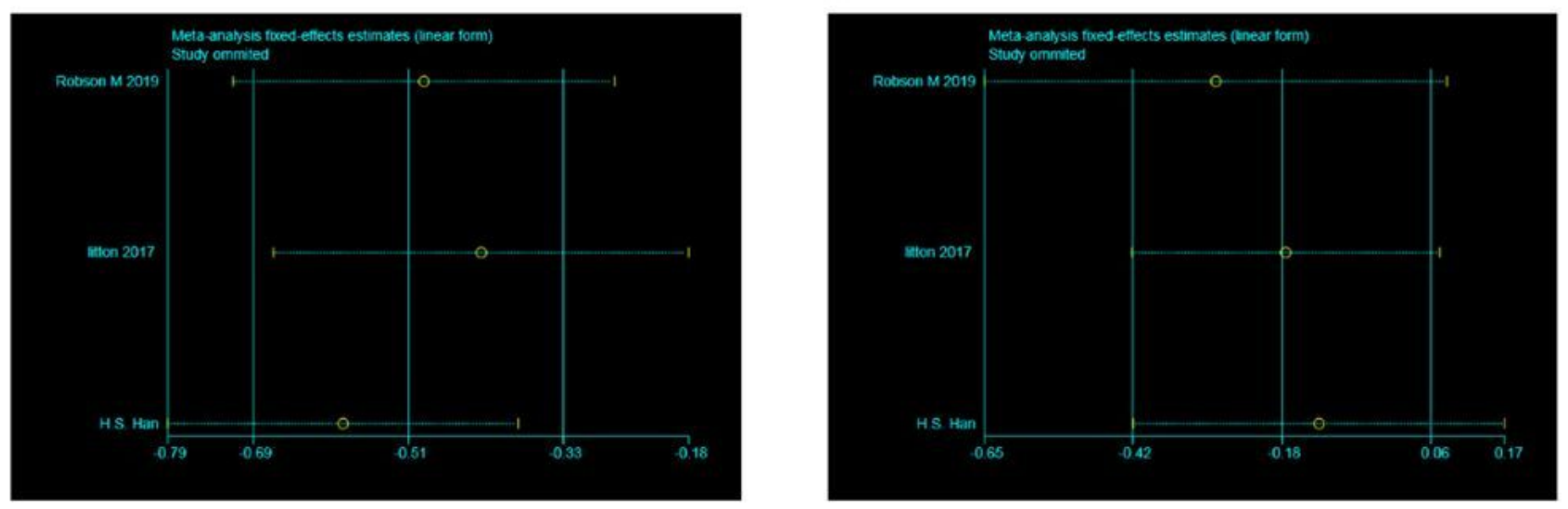

\section{Figure 5}

Sensitivity analyses for included studies.a.all studies concerning PFS. b.all studies concerning OS

a

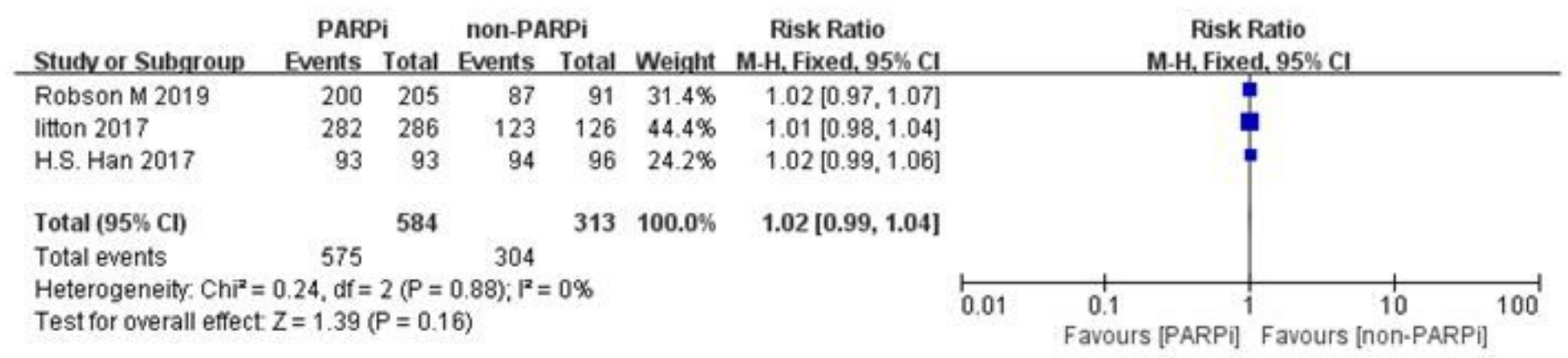

b

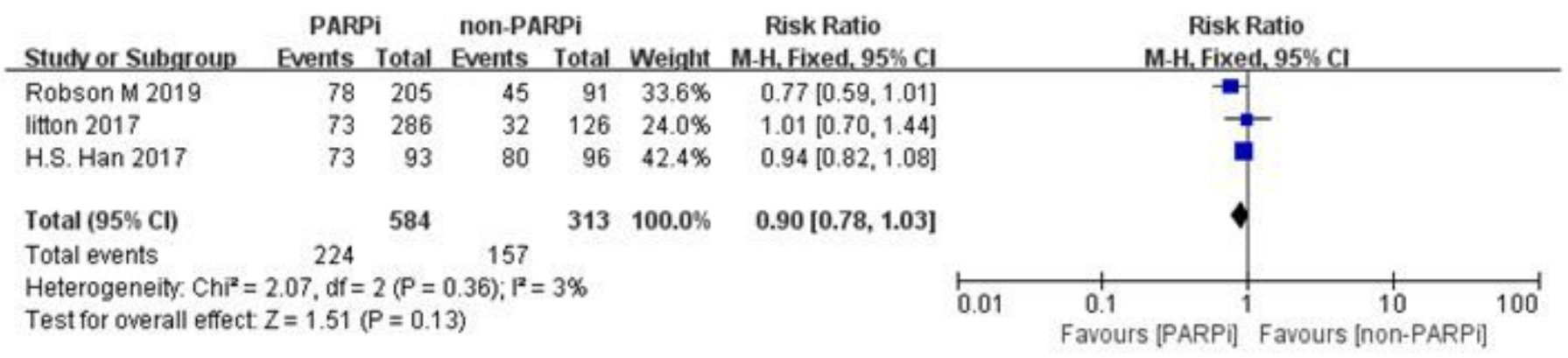

\section{Figure 6}

Relative risk of all-grade (a) and grade 3 or more (b) adverse events associated with PARPi versus nonPARPi. 

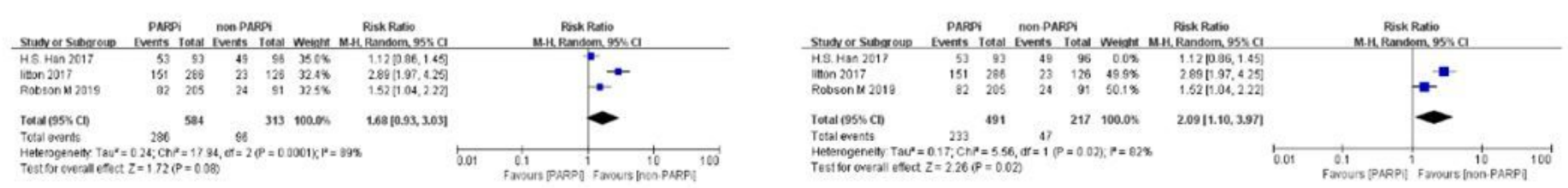

b

b1
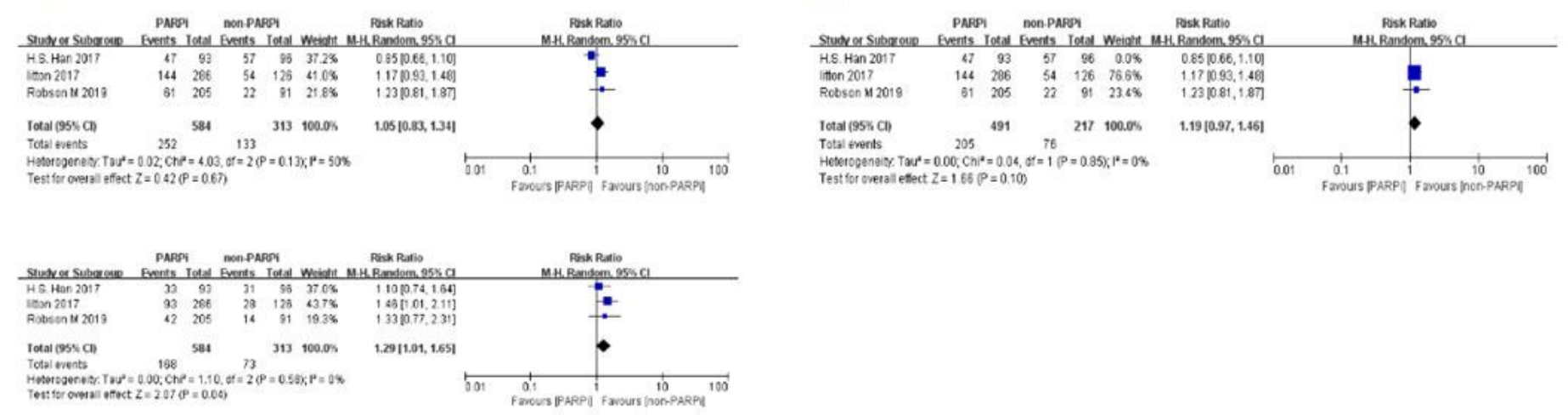

Figure 7

Relative risk of all-grade anemia (a) ,fatigue (b) and headache (c)events associated with PARPi versus placebo/control in stratified analysis after excluding trial thatPARPi was in combination with chemotherapy(a1)and( b1).

a

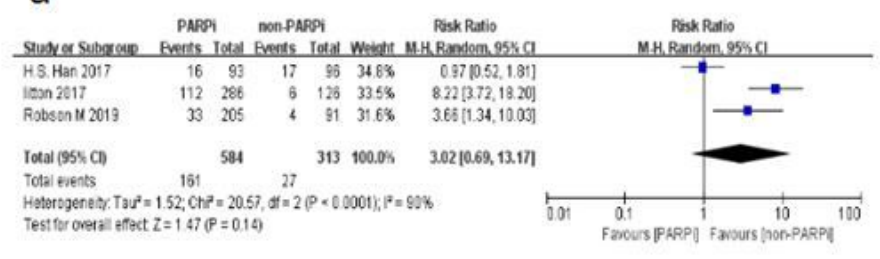

a1

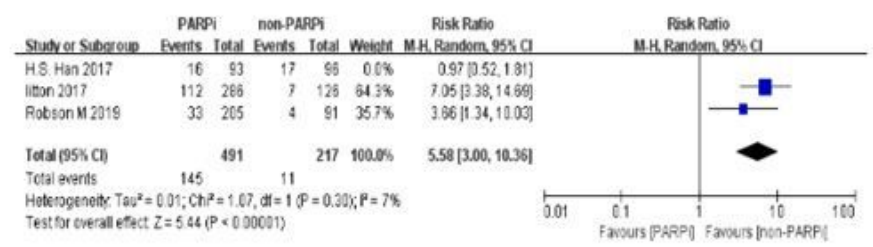

b

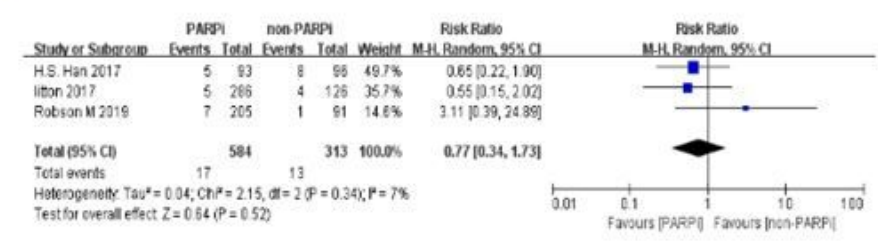

C

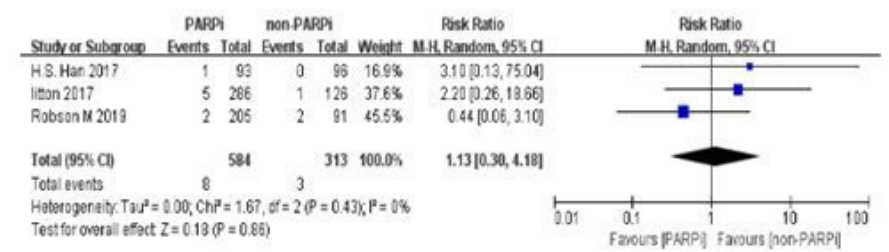

\section{Figure 8}

Relative risk of grade 3 or more anemia (a) $\nabla$ fatigue (b) and headache (c)events associated with PARPi versus placebo/control in stratified analysis, (a1)when evaluating only trials that PARPi was given as monotherapy. 